\title{
A Study on the Effect of Museum Art Exhibition Service Quality on Customer Satisfaction
}

\section{미술관 전시서비스품질이 고객만족도에 미치는 영향에 관한 연구}

Daim Jung ${ }^{1}$, Hakyun Kim²

정다임 ${ }^{1}$, 김하균 ${ }^{2}$

${ }^{1}$ Doctoral Student, 48513 Graduate School of Information Systems, Pukyong National Univ. 45, Yongso-ro, Nam-Gu. Busan, Korea,polo7336@naver.com

${ }^{2}$ Professor, 48513 Division of Business, Pukyong National Univ. 45, Yongso-ro, Nam-Gu. Busan, Korea, kimhk@pknu.ac.kr

Corresponding author: Hakyun Kim

\begin{abstract}
In modern society, art galleries have expanded beyond the traditional role of preservation and exhibition of artistic creations to various communication spaces for citizens. Therefore, evaluation and analysis of exhibition service quality should be preceded for the management innovation of art galleries and differentiated customer service. Exhibits are the museum's most important activity, meaning the public presentation of works of art in designated places for a period of time. In this study, we identified the service properties of exhibition services in Korean art galleries, which are focused on art exhibitions, and presented the composition factors of the services, and analyzed how these factors affect perceived performance and customer satisfaction. The factors that determine the type of exhibition service quality were communication, reliability, reputation of exhibits, information and purchase rationality. The results of the study are as follows. First, communication had no significant impact on perceived performance. Second, reliability had a significant impact on perceived performance. Third, the reputation of the exhibits had a significant impact on perceived performance. Fourth, informativeness had a significant impact on perceived performance. Fifth, purchasing rationality had a significant impact on perceived performance. Sixth, perceived performance had a significant impact on customer satisfaction.
\end{abstract}

Keywords: Museum, Exhibition Service Quality, Perceived Performance, Customer Satisfaction

요약: 현대사회에서 미술관은 예술 창작품의 보존과 전시라는 전통적 역할을 넘어 시민들의 다양한 소통공간으로 확장되어 가고 있다. 따라서 미술관의 경영혁신과 차별화된 고객서비스를 위해서는 전시서비스품질의 평가와 분석이 선행되어야 할 것이다. 전시회는 박물관의 가장 중요한 활동으로, 일정 기간 동안 지정된 장소에 예술 작품을 공개 발표하는 것을 의미한다. 본 연구에서는 미술 전시를 주목적으로 하는 국내 미술관의 전시서비스에 대한 서비스 속성을 파악하고 서비스의 구성 요인을 제시하여 그 요인들로 인해 지각된 
성과와 고객만족도에 어떠한 영향을 미치는지를 분석하였다. 전시서비스품질 유형을 결정하는 요인으로는 소통성, 신뢰성, 전시품의 명성, 정보성, 구매 합리성으로 구분하였다. 연구의 결과는 다음과 같다. 첫째, 소통성은 지각된 성과에 유의한 영향을 미치지 않았다. 둘째, 신뢰성은 지각된 성과에 유의한 영향을 미쳤다. 셋째, 전시품의 명성은 지각된 성과에 유의한 영향을 미쳤다. 넷째, 정보성은 지각된 성과에 유의한 영향을 미쳤다. 다섯째, 구매합리성은 지각된 성과에 유의한 영향을 미쳤다. 여섯째, 지각된 성과는 고객만족도에 유의한 영향을 미쳤다.

핵심어: 미술관, 전시서비스품질, 지각된 성과, 고객만족도

\section{1. 서론}

현대사회에서 미술관은 예술 창작품의 보존과 전시라는 전통적 역할을 넘어 시민의 다양한 소통공간으로 확장되어 지역경제를 활성화하는 기여하고 있다. 문화예술기관도 무한경쟁 상황에서 살아남기 위해서는 경영혁신이 필요하다. 미술관이란 문화, 예술의 발전과 일반 공중의 문화 향유 증진에 이바지하기 위하여 박물관 중에서 특히 서화, 조각, 공예, 건축, 사진 등 미술에 관한 자료를 수집, 관리, 보존, 조사, 연구, 전시 및 교육하는 시설을 말한다[1]. 미술관에서 가장 핵심적인 활동은 전시회이다.

최근 미술관은 전통적 기능을 넘어 경제 창출의 요소로 인식되면서 국내의 각 지방자치단체와 사립 기관의 주도로 다양한 형태의 전시회가 활발하게 진행되고 있다. 2018년 국내 국공립 및 사립 미술관 전체의 수는 244개로 2008년 127 개에 비해 $48 \%$ 이상 증가했으며, 다양한 미술 전시의 확장과 함께 전시 관람자에 대한 서비스 품질의 인식 개선도 요구되고 있다[2]. 이에 비해 우리나라의 미술관과 전시 관람객들의 특성을 반영한 서비스품질 측정 요인에 대한 연구 또한 매우 부족한 실정이다. 미술전시의 경우는 경영의 개념이 아닌 비술품의 보여주기에 초점을 두고 있어 관람객의 눈높이를 맞추기가 힘들다. 이것은 미술품에 대한 관광객의 욕구와 미술품을 소장하고자 하는 소비자의 관점을 파악하지 못하는 것이다.

따라서 본 연구에서는 서브퀄(SERVQUAL)과 히스토퀄(HISTOQUAL)의 측정 요인들을 포괄할 수 있는 척도를 선정하여 미술관의 전시서비스품질이 고객만족도에 미치는 영향을 분석하고자 하였다[3]. 선행연구 결과를 기반으로 국내 미술관의 전시서비스품질 유형을 결정하는 요인으로 소통성, 신뢰성, 전시품의 명성, 정보성, 구매합리성으로 구분하였다. 이를 통해 전시서비스품질에 대한 만족도를 제고할 수 있는 핵심적이고 일관성 있는 척도의 도출을 통해 바람직한 미술관 운영 방향을 제시하고자 한다. 미술품을 관람하는 고객이 존재하는 미술관의 특성상 서비스 품질에 대한 측정은 경영성과와 직결된 요인으로 볼 수 있을 것이다. 이에, 전시소비자들의 지각된 성과와 다각적인 영향 관계에 대한 규명을 통해 미술관의 경영성과를 제고할 수 있을 것으로 기대한다. 각 요인 간 관계를 검정하기 위해 구조방정식 패키지 Smart PLS 2.0을 사용하였다. 


\section{2. 이론적 배경}

\section{1 전시서비스품질}

서비스품질에 대해서는 연구자와 학문 분야에 따라 다양하게 정의되고 있다. 서비스는 크게 무형성(intangible), 이질성(heterogeneous), 비분리성(inseparable), 소멸성(extinctive) 의 특성을 들 수 있다[4]. 서비스품질을 측정하기 위한 도구로는 $\mathrm{PZB}[5]$ 가 개발한 서브퀄 (SERVQUAL) 모형이 최초이며, 현재 서비스품질에 대한 측정 도구로 가장 많이 사용되고 있다. 서브퀄(SERVQUAL)은 최초 10개의 평가 요인으로 구성되었다. 이후 1988년 실증연 구를 통해 유형성, 신뢰성, 반응성, 확신성, 공감성 5 개, 22 개의 평가 항목으로 정리되었 다. 이에 따라 서브퀄(SERVQUAL)은 22개의 같은 평가항목을 사용하여 소비자가 기대 서 비스에 대해 측정하고, 소비자가 지각하는 서비스 성과에 대해 측정하여 기대와 성과의 차이로 서비스 품질을 측정하게 된다. 이 후 여러 연구를 통해 대표적인 서비스품질 측 정 도구로 지지받았으며, 서비스의 속성에 따라 요인이나 평가항목을 가감하여 사용하는 것이 지배적이다[5][6].

히스토퀄(HISTOQUAL) 모형은 문화유산 관광지의 서비스품질 평가에 적합한 평가요소를 도출하기 위하여 문화산지를 대상으로 연구를 진행한 결과, 공감성(empathy), 유형성(tangibles), 대응성(responsive), 소통성(communication), 소비성(consumable) 등의 5 개 요소가 적합하다고 연구되었다. 히스토퀄(HISTOQUAL) 방식으로 측정한 데이터의 분석 결과는 서브퀄(SERVQUAL) 데이터의 결과치보다 더 우수한 것으로 나타났다[3][7].

권혁인 외는 전시서비스품질을 소통성, 신뢰성, 전시품의 명성, 정보성, 편의 접근성, 부가서비스의 다양성, 구매합리성, 전시품의 다양성 등으로 나누어 제시하였다[6]. 본 연구의 전시서비스품질 평가항목 중 소통성은 전시 관람객과 직원 간 원활하고 즉각적인 소통을 통한 신속하고 정확한 전시서비스를 제공하는 것이다. 신뢰성은 전시 관람객과 전시 시설 및 직원 간 믿고 의지할 수 있는 성질이다. 전시품의 명성은 전시품, 작가 및 전시회의 높은 평판이며, 정보성은 다양한 홍보를 통해 전시 관람객이 관람 전 접한 정보이며, 구매합리성은 티켓 가격, 구매방법 및 판매가격에 대한 적정성이다.

\section{2 지각된 성과}

지각된 성과란 특정 제품의 서비스를 직접 체험한 소비자가 해당 제품의 서비스에 대한 사후 이미지를 평가하는 것으로 일종의 체험에 대한 태도라고 정의된다[8][9]. 어떤 제품을 소비하거나 서비스를 사용하였을 경우, 소비자는 이에 대한 평가를 내리게 된다. Bagozzi는 개인의 제품 구매와 같은 활동은 특정한 기대 욕구에 의한 것이며, 이와 같은 활동에 대한 결과가 기대했던 성과로 지각되면 만족을 얻게 되는 것이라고 하였다[10]. 이러한 현상을 설명하기 위하여 Oliver는 기대불일치 이론(Disconfirmation Theory)을 제시하였다[11]. 이는 소비자들이 인지하는 제품의 품질은 제품의 객관적인 품질 이외에도 주관적 기대가 함께 작용하여 결정된다는 것이다. 이러한 소비자의 주관적 가치평가에 대한 연구는 주로 만족이라는 결과 변수와 연관되어, 소비자 만족에 미치는 영향 연구로 수행되어 왔다. 기대불일치 이론은 가장 대표적인 이론으로서 소비자의 기대와 불일치, 만족과 구매의도의 연관성을 규명하였다[12]. 김성수 외는 신규 IT 서비스 
사용자의 지각된 서비스품질과 이용자 만족도에 대한 영향을 조사한 결과, 지각된 성과는 서비스 만족도에 유의미한 영향이 미치는 것을 검증하였다[13].

\section{3 고객만족도}

고객만족도는 오늘날 마케팅 사고의 핵심적 개념으로 이해되고 있으며 학계에서 다양한 관점으로 연구되어 왔다. 지금까지 고객만족에 관한 연구는 양적인 발전에 비해서 미비한 이론적 토대로 학자들 간에도 다양한 내용으로 정의되고 있다. Howard 외는 고객이 지불한 대가에 대해 적절하게 보상되었는지를 느끼는 심리적 인지상태라고 정의하였고, Czepiel 외는 고객 욕구와 요구의 충족도 정도에 대한 소비자 개인의 주관적인 평가라고 정의하고 있다[14][15]. Pfau 외는 외부 고객만족은 내부 고객만족의 산물이라고 지적하면서 내부 근무자가 파악하고 전달할 수 있는 능력 등이 고객만족의 중요한 요소임을 제시하였다[16]. Hayes는 서비스품질 중 대응성, 유희성 등과 같은 요인은 내부 서비스 제공자와 관계가 있음을 제시하였다[17]. 전시관람객의 만족은 마케팅 전략상 소비자 구매의사결정 과정의 결과 변수로 작용하는 중요한 개념이다. 고객만족은 “고객의 욕구(Needs)와 기대(Expect)에 최대한 부응하여 그 결과로서 상품과 서비스의 재구입이 이루어지고 아울러 고객의 신뢰감이 연속적으로 이어지는 상태” 를 말한다[18]. 기존의 많은 연구에서 서비스품질이 향상되면 고객만족도가 증가되고 이는 재구매에 긍정적인 영향을 미친다는 사실을 증명하였다.

\section{3. 연구설계}

\section{1 연구모형}

본 연구는 미술관에서 제공하는 서비스를 중심으로 미술품 전시서비스품질과 지각된 성과와 고객만족도의 영향관계를 알아보고자 하였다. 이러한 목적을 달성하기 위하여 국내 미술품 전시서비스품질이 타 서비스 산업과 변별되는 제반 특성을 고려하여, 서비스 영향 요인의 척도로 제시한 서브퀄(SERVQUAL) 모형과 한국 미술 전시서비스품질 측정 항목[6]을 사용하였다. 선행연구에서 제시한 미술 전시품질 측정 항목인 소통성, 신뢰성, 전시품의 명성, 부가서비스의 다양성, 정보성, 구매합리성, 편의 접근성, 전시품의 다양성 등의 7 개 요인 중 본 연구의 목적에 맞게 소통성, 신뢰성, 전시품의 명성, 정보성, 구매합리성 등의 5 개 요인으로 재구성하였다. 가설 검정을 위해 설문조사 방법을 사용하였다. 선행연구를 기반으로 제안한 연구의 모형은 [그림 1]과 같다.

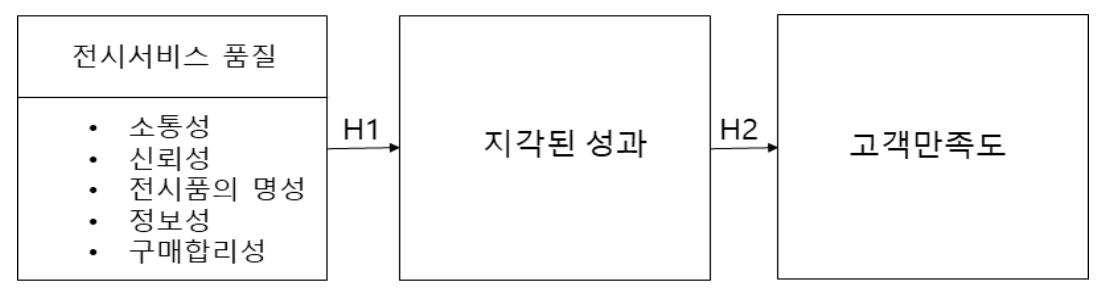

[그림 1] 연구 모형

[Fig. 1] Research Model 


\section{2 연구가설}

전시서비스품질의 특성을 연구한 선행연구에서는 소통성, 신뢰성, 전시품의 명성, 정보성, 편의 접근성, 부가서비스의 다양성, 구매합리성, 전시품의 다양성 등으로 구분하였다[6]. 본 연구에서는 선행연구의 측정 항목을 가감하여 미술관 서비스품질의 요인을 소통성, 신뢰성, 전시품의 명성, 정보성, 구매합리성으로 선정하였다.

가설 H1-1 소통성은 지각된 성과에 유의적인 영향을 미칠 것이다.

가설 H1-2 신뢰성은 지각된 성과에 유의적인 영향을 미칠 것이다.

가설 H1-3 전시품의 명성은 지각된 성과에 유의적인 영향을 미칠 것이다.

가설 H1-4 정보성은 지각된 성과에 유의적인 영향을 미칠 것이다.

가설 H1-5 구매합리성은 지각된 성과에 유의적인 영향을 미칠 것이다.

품질이 객관적으로 동일한 제품을 구매하였다 하더라도 소비자들의 만족 수준은 각각 다를 수 있다. 또한 소비자들이 어떠한 제품 및 서비스를 사용할 경우 사전에 인식된 기대와 실제 사용 후 인식하는 품질의 평가는 차이가 있을 수도 있다. 사전 기대와 지각된 성과에 대한 차이는 결국 소비자의 만족과 제품의 평가에 영향을 미치게 된다. 본 연구에서는 선행연구를 바탕으로 가설을 설정하였다.

가설 $\mathrm{H} 2$ 지각된 성과는 고객만족도에 유의적인 영향을 미칠 것이다.

\section{4. 실중분석 및 결과}

설문지의 기본통계분석을 위해 통계 패키지인 SPSS 22.0 을 사용하였다. 가설 검정을 위해 구조방정식 패키지인 Smart PLS 2.0을 활용하여 집중타당성과 판별타당성을 검증하였다. 요인적재 값, Cronbach' $\alpha$, 구성신뢰도(Composite Reliability) 및 각 요인의 평균분산추출값(Average Variance Extraction)을 검증하였다. 요인적재값은 0.6 이상, Cronbach' $\alpha$ 값은 0.7 이상, 구성신뢰도값은 0.7 이상, 및 0.5 이상의 분산추출지수값이 일반적으로 유효한 것으로 간주된다.

\section{1 자료수집 및 표본의 특성}

3 년 이내에 2회 이상 미술관을 방문하여 미술품을 관람한 일반인 110 명이 한 달 동안 서면 및 온라인 설문조사에 참여했다. 연구목적에 가장 적합한 사람을 대상으로 의도적 표집(purposive sampling)을 하였다. 기본통계조사를 살펴보면 다음과 같다. 응답자의 연령 은 40 대 이상이 $76.4 \%$ 이며, 30 대 이하가 $23.6 \%$ 이다. 성별은 남자가 $49.1 \%$, 여자가 $50.9 \%$ 로 큰 차이가 없다. 최종 학력은 대학원 졸업이 $46.8 \%$, 대학 졸업이 $43.1 \%$ 로 전체 응답자 의 $89.9 \%$ 로 대부분을 차지하였으며, 직업은 전문직이 $46.4 \%$, 자영업 및 회사원이 $18.2 \%$ 로 나타났다. 최근 3 년 동안 미술 전시장 방문 횟수는 10 회 이하가 $37.3 \%, 10$ 회 이상이 $10 \%$ 라고 응답하였으며, 이 중 2회 이상이 $52.7 \%$ 로 나타났다.

\section{2 자료의 분석방법}

집중타당성의 결과는 [표 1]과 같다. 판별타당성의 결과는 [표 2]와 같다. 
[표 1] 신뢰도 및 집중타당성 분석 결과

[Table 1] Reliability and Internal Consistency Results

\begin{tabular}{|c|c|c|c|c|}
\hline 변수 & 요인적재 값 & AVE & C. R. & Cronbach's \\
\hline \multirow{5}{*}{ 소통성 } & 0.723 & \multirow{5}{*}{0.597} & \multirow{5}{*}{0.886} & \multirow{5}{*}{0.831} \\
\hline & 0.812 & & & \\
\hline & 0.717 & & & \\
\hline & 0.839 & & & \\
\hline & 0.763 & & & \\
\hline \multirow{6}{*}{ 신뢰성 } & 0.809 & \multirow{6}{*}{0.649} & \multirow{6}{*}{0.917} & \multirow{6}{*}{0.892} \\
\hline & 0.818 & & & \\
\hline & 0.851 & & & \\
\hline & 0.809 & & & \\
\hline & 0.782 & & & \\
\hline & 0.761 & & & \\
\hline \multirow{3}{*}{ 전시품의 명성 } & 0.865 & \multirow{3}{*}{0.729} & \multirow{3}{*}{0.890} & \multirow{3}{*}{0.814} \\
\hline & 0.869 & & & \\
\hline & 0.827 & & & \\
\hline \multirow{5}{*}{ 정보성 } & 0.836 & \multirow{5}{*}{0.735} & \multirow{5}{*}{0.933} & \multirow{5}{*}{0.910} \\
\hline & 0.854 & & & \\
\hline & 0.885 & & & \\
\hline & 0.843 & & & \\
\hline & 0.868 & & & \\
\hline \multirow{3}{*}{ 구매합리성 } & 0.801 & \multirow{3}{*}{0.714} & \multirow{3}{*}{0.882} & \multirow{3}{*}{0.802} \\
\hline & 0.868 & & & \\
\hline & 0.864 & & & \\
\hline \multirow{5}{*}{ 지각된 성과 } & 0.847 & \multirow{5}{*}{0.670} & \multirow{5}{*}{0.910} & \multirow{5}{*}{0.910} \\
\hline & 0.826 & & & \\
\hline & 0.831 & & & \\
\hline & 0.885 & & & \\
\hline & 0.727 & & & \\
\hline \multirow{5}{*}{ 고객만족도 } & 0.870 & \multirow{5}{*}{0.699} & \multirow{5}{*}{0.920} & \multirow{5}{*}{0.892} \\
\hline & 0.889 & & & \\
\hline & 0.826 & & & \\
\hline & 0.821 & & & \\
\hline & 0.769 & & & \\
\hline
\end{tabular}


[표 2] 상관관계 및 판별 타당성 분석 결과

[Table 2] Correlation and Discriminant Validity

\begin{tabular}{|c|c|c|c|c|c|c|c|}
\hline 변수 & $\mathrm{AVE}$ & 1 & 2 & 3 & 4 & 5 & 6 \\
\hline 소통성 & 0.597 & & & & & & \\
\hline 신뢰성 & 0.649 & 0.805 & & & & & \\
\hline 전시품의 명성 & 0.729 & 0.683 & 0.853 & & & & \\
\hline 정보성 & 0.735 & 0.345 & 0.506 & 0.857 & & & \\
\hline 구매합리성 & 0.714 & 0.551 & 0.601 & 0.578 & 0.844 & & \\
\hline 지각된 성과 & 0.670 & 0.734 & 0.761 & 0.721 & 0.544 & 0.818 & \\
\hline 고객만족도 & 0.699 & 0.609 & 0.739 & 0.653 & 0.798 & 0.677 & 0.836 \\
\hline
\end{tabular}

\section{3 연구 모형의 검중}

구조 모형은 Smart PLS 2.0을 사용하였으며 구조 모형을 통해서는 연구 모형의 변수들 간의 경로계수와 결정계수(R2) 결과값을 도출하였다.

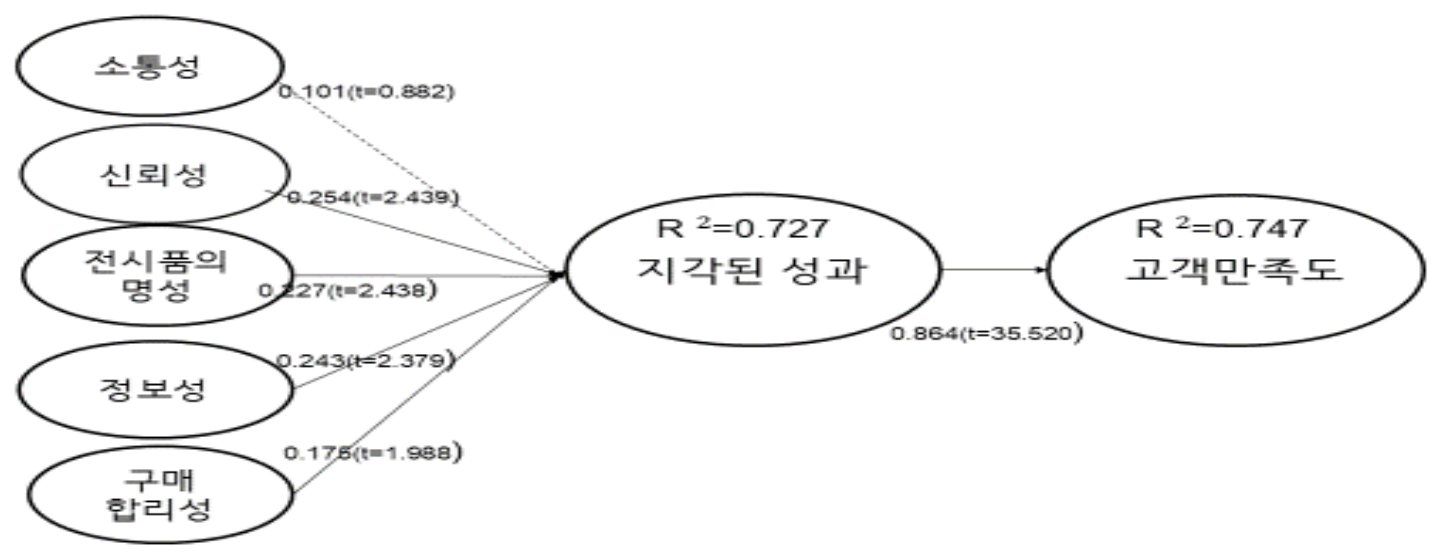

[그림 2] 구조모형 분석 결과

[Fig. 2] The Results of Research Model

가설 $\mathrm{H} 1$ 은 부분 채택되었고, $\mathrm{H} 2$ 는 채택되었다. 첫째, 가설 $\mathrm{H} 1-1$ 의 “소통성은 지각된 성과에 영향을 미칠 것이다.” 라는 가설은 기각되었다. 소통성은 지각된 성과 $(\beta=0.101$, $\mathrm{t}=0.882, \mathrm{p}<0.378)$ 에 유의한 영향을 미치지 않는 것으로 나타났다. 둘째, 가설 $\mathrm{H} 1-2$ “신뢰성은 지각된 성과에 영향을 미칠 것이다.” 라는 가설은 채택되었다. 신뢰성은 
지각된 성과 $(\beta=0.254, \mathrm{t}=2.439, \mathrm{p}<0.05)$ 에 유의한 영향을 미치는 것으로 나타났다. 셋째, 가설 H1-3의 “전시품의 명성은 지각된 성과에 영향을 미칠 것이다.” 라는 가설은 채택되었다. 전시품의 명성은 지각된 성과 $(\beta=0.227, \mathrm{t}=2.438, \mathrm{p}<0.05)$ 에 유의한 영향을 미치는 것으로 나타났다. 넷째, 가설 H1-4의 “정보성은 지각된 성과에 영향을 미칠 것이다.” 라는 가설은 채택되었다. 정보성은 지각된 성과 $(\beta=0.243, \mathrm{t}=2.379, \mathrm{p}<0.05)$ 에 유의한 영향을 미치는 것으로 나타났다. 다섯째, 가설 H1-5의 “구매합리성은 지각된 성과에 영향을 미칠 것이다.” 라는 가설은 채택되었다. 구매합리성은 지각된 성과 $(\beta=$ $0.175, \mathrm{t}=1.988, \mathrm{p}<0.05)$ 에 유의한 영향을 미치는 것으로 나타났다. 여섯째, 가설 $\mathrm{H} 2$ 의 “지각된 성과는 고객만족도에 영향을 미칠 것이다.” 라는 가설은 채택되었다. 지각된 성과는 고객만족도 $(\beta=0.864, \mathrm{t}=35.520, \mathrm{p}<0.05)$ 에 유의한 영향을 미치는 것으로 나타났다.

[표 3] 가설검정 결과 요약

[Table 3] Results of Hypothesis Tests for the Research Model

\begin{tabular}{|l|c|c|c|}
\hline 가설 경로 & 표준화 계수 $(\beta)$ & $\mathrm{t}$-value & 채택 유무 \\
\hline $\mathrm{H} 1.1:$ 소통성 $\rightarrow$ 지각된 성과 & 0.101 & 0.882 & 기각 \\
\hline $\mathrm{H} 1.2:$ 신뢰성 $\rightarrow$ 지각된 성과 & 0.254 & 2.439 & 채택 \\
\hline $\mathrm{H} 1.3:$ 전시품의 명성 $\rightarrow$ 지각된 성과 & 0.227 & 2.438 & 채택 \\
\hline $\mathrm{H} 1.4:$ 정보성 $\rightarrow$ 지각된 성과 & 0.243 & 2.379 & 채택 \\
\hline $\mathrm{H} 1.5:$ 구매 합리성 $\rightarrow$ 지각된 성과 & 0.175 & 1.988 & 채택 \\
\hline $\mathrm{H} 2:$ 지각된 성과 $\rightarrow$ 고객만족도 & 0.864 & 35.520 & 채택 \\
\hline $\mathrm{t}=1.97^{*}, \mathrm{p}<0.05$ & \multicolumn{3}{|l}{} \\
\hline
\end{tabular}

\section{5. 결론}

본 연구는 전시서비스품질(소통성, 신뢰성, 전시품의 명성, 정보성, 구매합리성)이 지각된 성과를 매개로 고객만족도에 어떤 영향을 주는지 알아보기 위한 실증 연구이다. 전시서비스품질, 지각된 성과, 고객만족도에 대한 선행연구 문헌을 정리하였다. 또한, 기존 연구를 바탕으로 전시서비스품질, 지각된 성과, 고객만족도에 대한 연구 모형과 연구 가설을 설정하였다. 본 연구의 실증분석 결과를 요약하면 아래와 같다. 첫째, 전시서비스 품질이 지각된 성과에 영향을 미친다는 가설 $\mathrm{H} 1$ 은 부분 채택되었다. 소통성은 지각된 성과에 유의한 영향을 미치지 않았다. 신뢰성은 지각된 성과에 유의한 영향을 미쳤다. 전시품의 명성은 지각된 성과에 유의한 영향을 미쳤다. 정보성은 지각된 성과에 유의한 영향을 미쳤다. 구매합리성은 지각된 성과에 유의한 영향을 미쳤다. 둘째, 지각된 성과는 고객만족도에 유의한 영향을 미쳤다는 가설 $\mathrm{H} 2$ 는 채택되었다.

본 연구의 시사점을 제시하면 다음과 같다. 첫째, 미술관의 전시서비스품질에 있어서 중요한 요인은 신뢰성, 전시품의 명성, 정보성의 순서이고, 전시 내용에 대한 사전 정보제공과 상호신뢰도에 따라 고객만족도에 중요한 영향을 미친다는 것이다. 
전시서비스품질 측정의 선행연구[6]에서 도출된 측정 항목이 전시서비스 소비자의 지각된 성과와 고객만족도에 영향을 미친다는 것을 본 연구에서도 실증 확인하였다. 둘째, 미술관 직원과 밀접 접촉 서비스품질 항목인 소통성이 기각되었다는 것은 코로나 19 와 같은 특수한 상황과 디지털 시대의 반영으로 고객들의 전시서비스 니즈가 변화되고 있다는 것을 시사한다고 할 수 있을 것이다. 본 연구는 향후 미술관 전시서비스품질에 대한 더욱 체계적인 연구의 연속성에 기여하고, 소비자 중심의 미술관 운영방안을 제시하였다는 점에서 의의가 있다.

\section{References}

[1] https://www.law.go.kr/lsSc.do?section=\&menuId=1\&subMenuId=15\&tabMenuId=81\&eventGubun=060101\&query=\%EB\% AF\%B8\%EC\%88\%A0\%EA\%B4\%80\%EB\%B2\%95\#undefined, Jan 4 (2021)

[2] https://www.gokams.or.kr, Jan 10 (2021)

[3] J. Park, S. Kim, J. Chung, Service quality measurement of Daegu Museum of Art by combining SERVQUAL and HISTOQUAL methods, The Korea Service Management Society, (2017), pp.73-81.

[4] V. A. Zeithaml, Delivering Quality Service, New York: The Free Press, (1990)

[5] A. Parasuraman, SERVQUAL: A multiple-item scale for measuring consumer perception of service quality, Journal of Retailing, (1988), Vol.64, No.1, pp.12-29.

[6] H. Kwon, H. Joo, J. Lee, Service Quality Measurement and Analysis of Consumer Service Condition for Korea Art Exhibition, Korean Journal of Business Administration, (2011), Vol.24, No.4, pp.2347-2364.

[7] H. Lee, A Study of Satisfactions and Behavior Intentions according to HISTOQUAL: A Sample of Tourists Visiting Jeonju Hanok Village, International Journal of Tourism and Hospitality Research, (2014), Vol.28, No.8, pp.71-81.

[8] E. H. So, K. R. Lee, Influence of Service Quality and Visit the Motivation on Visitors Satisfaction, Behavioral Intention in Museum -Focused on National Museum of Korea, The Korea Contents Association, (2014), Vol.14, pp.515-527.

[9] S. Burton, L. A. Babin, Decision-Framing Helps make the Sale, Journal of Consumer Marketing, (1989), Vol.6, No.2, pp.15-24.

[10] R. P. Bagozzi, The Self-Regulation of Attitudes, Intentions and Behavior, Social Psychology Quarterly, (1992), Vol.55, pp.178-204.

[11] D. K. Tse, P. C. Wilton, Models of Consumer Satisfaction Formation: An Extension, Journal of Marketing Research (1988), Vol.25, pp.204-212.

[12] R. L. Oliver, Measurement and Evaluation of Satisfaction Processes in Retail settings, Journal of Retailing, (1981), Vol.57, No.3, pp.25-48.

[13] S. Kim, C. Jung, Effects of the Degree of Match between Prior Expectation and Perceived Performance on User Satisfaction in New IT Services, Asia-pacific Journal of Multimedia Services Convergent with Art, Humanities, and Sociology, (2017), Vol.7, No.5, pp.845-852.

[14] J. A. Howard, J. N. Sheth, The Theory of Buyer Behavior, New York: John Wiley \& Sons, (1969)

[15] J. A. Czepiel, L. J. Rosenberg, Consumer Satisfaction: Toward and Integrative Framework, Proceedings of the Southern Marketing Association, (1976), pp.169-171.

[16] B. Pfau, D. Detzel, A. Geller, "Satisfy your internal customer, Journal of Business Strategy, (1991), Vol.12, No.6, pp.9-13. 
[17] B. E. Hayer, Measuring customer satisfaction: Development and use of questionnaires, Milwaukee: ASQC Quality, (1992)

[18] B. Lee, I. Jeon, Effect of Service Quality on Corporate Performance, Customer Satisfaction and Intention: Focus on Outsourcing of Exhibition/Convention Industry, (2012), pp.275-298. 